\title{
Vocational career in people in recovery: an exploratory study
}

\begin{abstract}
Considering the low employment figures of people in recovery their vocational rehabilitation should be revised. It is indicated that the rehabilitation philosophy of the WHO International Classification of Functions and some of the new approaches in career counselling, such as in Young and colleagues1 are providing a conceptualisation, which could be considered. This would be a shift from focussing on patients' dispositions to the occupational career related joint projects. Five exploratory interviews complemented by a self-confrontation interview with these people in recovery are discussed. We indicate the way, how a vocational career could become a rehabilitation guideline for all participating professions (psychotherapy, psychiatry, social work, occupational work) and how the work on it would turn into an occupational career related project.
\end{abstract}

Keywords: mental health, psychotherapy, social work, vocational rehabilitation, joint projects, career, action theory
Volume 3 Issue 6 - 2018

\author{
Valach Ladislav \\ Lindenstrasse 26, 3047 Bremgarten, Switzerland
}

Correspondence: Ladislav Valach, Lindenstrasse 26, 3047 Bremgarten, Switzerland, Email ladislav.valech@swissonline.ch

Received: November 272018 | Published: December II, 2018

\section{Introduction}

There seems to be a wide dissatisfaction with the outcome of the rehabilitation of people in recovery as their employment figures are low. Many of the people in recovery seek work but have not been successful in the labor market. ${ }^{2}$ While there appears to be a consensus among rehabilitation professionals that employment is an important part of life for persons with psychiatric disability, ${ }^{3}$ estimates of unemployment for the working-age members of this population are at a rate of around $85 \%$ in the US (National Institute of Disability and Rehabilitation Services, 1993). ${ }^{4}$ Even with a help of the vocational services their success rates are only about half of those with physical disabilities. ${ }^{5}$ Switzerland has, in comparison to many other industrialized countries a very low unemployment, indicating high participation in work and these figures have not changed much in last forty years. It has even been suggested that it is very difficult in many occupations to find the adequately qualified personal. Nevertheless, it has been reported ${ }^{6}$ that less than $50 \%$ of the patients with psychiatric disability were employed during the year prior to their hospitalization. The authors found six variables relevant for the prediction of the employment of the patients: gender (females having less chance to be employed), working experience ( $\%$ of lifetime) $(27 \%$ or less indicating lower chance for employment), education ('no vocational training' is linked with lower chance), number of prior hospitalizations (7 and more hospitalizations in life predict unemployment), number of hospitalization days during the last year (52 and more lower the chance of employment substantially) and diagnosis (affective disorder proves to be more inhibitive than schizophrenia).

It may seem a clear-cut picture that someone who was hospitalized last year for longer than two months could lose his/her job. This may become even more obvious if this hospitalization was the eighth one or more in the life of the person. However, the authors ${ }^{6}$ report that the groups of the employed and unemployed persons, though differing in means of these variables possess a standard deviation of these variables which is mostly higher than the mean thus indicating a substantial overlap. Consequently, there are many persons with a few hospitalization days during the year prior hospitalization who are unemployed as well as persons who were less often hospitalized than the average of the employed persons and who are, nevertheless, unemployed.

Often, various social aspects outside of mental health care are used to account for this fact, such as public labeling of and unjustified distancing from former mental health patients or the current state of economy, the employment market and the diminishing social consciousness of the employers. However, many mental health rehabilitation professionals also reflect about the occupational and vocational rehabilitation in mental health. The improvement in the person in recovery condition while being hospitalized is not a guarantee for his or her social integration including employment after being discharged. The persons in recovery need careful and precise discharge plans, often with special rehabilitation programs. ${ }^{7}$ The discussion about what the best procedure to implement in order to reach a better employment figures indicates the conviction that something should and could be done to improve this situation. Adolph Meyer, ${ }^{8}$ together with Eleanor Clarke Slagle and John Dewey shared a vision that social problems can be ameliorated and they were united in hope in the healing process of occupation and community.

Various procedures to integrate the former mental health patients into the occupational world have been tried and evaluated. Presently, the discussion between those who promote the view that patient should be extensively trained before entering the occupational market and those suggesting that patients should be active in the competitive job market as soon as possible but that they should receive long support underway seems to indicate that the later position is gaining more empirical evidence and this strategy is presently known as supported employment. We believe that this strategy is successful because the right occupational career related joint projects are launched.

In this article we would like to point out some issues discussed and conceptualized in the vocational career counseling which might provide a lead to a new and more focused attempt achieving a better social integration of persons in recovery. In addition, the 
preliminary findings or insights won in five interviews of occupational therapists and social workers with persons in recovery will be reported and examined whether or not they support the suggested conceptualization. These five interviews will be used to illustrate the proposed conceptualization.

\section{Conceptual considerations}

The core of this consideration is based on the belief that additional than mental health conceptualization is required when planning the occupational and vocational rehabilitation processes of persons in recovery. This conceptualization should go beyond the idea that a person with mental health challenges should learn additional skills required for the job and that a matching position, which would cater for the person's deficits should be found for this person. This type of thinking used to be popular in occupational and vocational counseling some decades ago. Then the person's dispositions were explored, the person's limits monitored and a fitting or matching job was sought for. ${ }^{9}$ However, it has recently been recognized in vocational career counseling that other type of conceptualization of the empirical analysis, of the developing of vocational processes, job search and job performance as well as vocational counseling are necessary. ${ }^{10,11}$ Some methodological and epistemological discussions were helpful in pointing out that the common model is a construction facilitated by certain tools of empirical analysis, which, however, might have already become obsolete. ${ }^{12}$ In this situation it was either sought for how to make the conceptualization formed by statistical methods of yesterday better adapted to the statistical methods of today or conceptualizations are suggested which are based on these contemporary statistical possibilities. However, the idea that these processes are constructed in everyday life and that these commonsense fabrics must be taken seriously for designing a fitting theoretical conceptualization is not generally shared..$^{13}$

One of these recent conceptualizations considering the everyday construction processes, respecting the contextual issues, answering many calls for epistemological and theoretical renewal of the theory of vocational counseling and of career is the contextual theory of goal directed action in career. ${ }^{1}$ This theory has been developed over the last 20 years ${ }^{14}$ and provides a conceptualization of vocational career related joint actions, projects and careers. It also describes the theoretically based methods of empirical analysis such as procedure for collecting data on subjective processes - the self-confrontation interview ${ }^{15}$ - the procedure for organizing the narratives of the concerned ${ }^{16}$ as well as the procedure for collecting data on social meaning. ${ }^{17}$ A comprehensive introduction in this theory and the research procedure including all methods can be found in Valach et al. ${ }^{18}$

\section{Theory}

The contextual theory of goal directed action views human behavior as organized in goal directed systems in forms of joint actions, projects and career. While actions are relatively short terms processes mostly extending over some minutes, projects are medium time forms lasting hours and days, careers imply long-term processes lasting some years. The theory sees each of the system organized at several levels. The top level is reserved for goal processes which provide the steering of the system, the medium level contains action or projects steps embodying control and the lowest level is design for the organization of the elements of actions and projects. Here the regulation processes are located. While the top levels are described in meaningful units using everyday language, the middle level requires functional categories for its descriptions and the lowest level, where the action elements are placed is best characterized with observational units using physical description of space, locomotion and sound. More relevant for the rehabilitation organization and understand than the technical features is the basic philosophy of this approach. It asks for processually defined units of ongoing individual, joint and organizational behavior. It does not ask for structural behavioral features such as dispositions. It sees human behavior as goal directed and not as caused by stable dispositional or structural factors. It sees human behavior as jointly constructed thus while respecting individual responsibility and empowerment it stresses the social nature of human behaviour.

Adopting this theory for consideration in mental health patients' vocational rehabilitation we will see the mental health patient vocational striving as a joint goal directed process in actions, projects and career of all concerned and we also will introduce the appropriate methods of data collection and analysis. Seeing the vocational career as a joint process we will maintain that the patient in talking to various mental health professionals will develop a certain vocation related project, which will be operational in facilitating certain vocational options. As the persons in recovery are engaged in numerous conversations with various professional participants and several narratives are constructed it becomes of interest to monitor these vocational project-constructing narratives. We believe that these occupational careers related joint projects are operational in launching the post in-patient treatment occupational projects and that the later are rooted in the former. Consequently, it is relevant that the right projects and career involving the right actions are constructed and that the constructed projects are compatible with the treatment goals of the patients and professionals.

Following this suggestion, it also implies that the rehabilitation professionals until now underestimated the projects developed together with patients and various rehabilitation therapists during the assessment and treatment, which were not instrumental in facilitating the patient's occupational career after their discharge from the inpatient treatment. One of the main reasons might be that although the interdisciplinary cooperation of rehabilitation professionals is increasing, the individual disciplines are leaning on their own, often incompatible, but mostly uncoordinated conceptualizations. The medical professionals follow a model, which differs from that of the occupational therapists and this is not identical with that of social workers. This is understandable then each group follows a model of deficits, which to compensate is their task. However, while accepting these three deficit models the patients develop projects and careers, which are helpful in steering their projects and careers after their discharge.

The aim of this report is to indicate how in a video-supported recall interview (self-confrontation interview) important background and further leading information can be obtained allowing us to understand the requirements and the important features of a patients' career and projects which would have to be attended to should the patient successfully follow an occupational career after discharge.

\section{Method}

\section{Subjects}

Five consecutive in-patients of the University Psychiatry Clinic who will be supported in their occupational and vocational rehabilitation 
by occupational and vocational therapists and rehabilitation professionals and social workers were interviewed with the standard interviewing procedure by occupational/vocational therapists asking about the vocational domain and / or by social workers asking about the segment of life for which social workers provide support such as living place, finances etc.

\section{Procedure}

The persons in recovery were asked to participate in the usual social work or vocation related interview in front of a TV camera and to view this recording afterwards together with a psychologist who would ask for further details. Prior to the interview they were asked to sign the informed consent to enable the research team to analyze these videotapes and to quote the patients' narratives in scientific publications.

The interviews conducted by an occupational therapist with persons in recovery consist of a semi-structured questioning in which the person is asked about his or her occupational life, previous jobs and positions and future plans. The persons are given plentiful time to elaborate on their answers. Objective data and subjective judgments are considered equally important. The interview conducted by a social worker with persons in recovery is also a semi-structured procedure in which the information on financial situation, living conditions and socio-economic standing of the patients is collected. Again, the persons are given satisfactory space to develop the theme to their satisfaction. While the occupational therapist's interview is conducted early in the in-patient treatment to provide additional information for occupational rehabilitation, the social worker's interview occurs later in the in-patient treatment, as it should provide information for the social work intervention prior to and following discharge.

These interviews lasted about 45 minutes each and were video recorded. The interviews were followed by a video-supported recall, which is labeled self-confrontation interview, which lasted about additional 90 minutes. The person in recovery and a psychotherapist viewed together the interview recording and the patients were asked, when the video recording was stopped each second or third minute after a meaningful unit (utterance etc.) ended, to report on any thoughts, feelings and sensations they had during the interview and add anything they wished.

\section{Ethical considerations}

The persons in recovery were asked to participate in the routine 'as usual' social work or vocation related interview but this time in front of a TV camera and in addition to this to view this recording together with a psychologist who would ask for further details. The persons received a copy of the recording if they wished to. Prior to the interview they were asked to sign the informed consent to enable the research team to analyze these videotapes and to quote the patients' narratives in scientific publications. They were informed that they could step down from the additional procedure whenever they wanted without any consequences. This was credible to them as the selfconfrontation interview was performed by an external psychologist not involved in the in-patient's treatment.

\section{Findings}

The first information we gained was that although some persons approached the video recording with some hesitance, they reported that they have soon forgotten the camera and were able to report in relaxed manner. They proved being competent narrators of their social occupational/vocational career. They particularly enjoyed the video self-confrontation interview and provided detailed reports on their thoughts and feeling during the interview as well as a number of valuable additional details and insights. During the self-confrontation interview it was also possible to address the emotions of the persons in recovery about various life and occupational career issues. Although some of them found it strenuous they all showed very committed and finished the procedure maintaining that they received extensive attention never given to them before while in treatment.

It became obvious that the persons in recovery developed their future occupational career plans around the mental health problems. The social workers and the vocational rehabilitation specialist would often follow this course.

\section{Examples}

A 49year old woman reported a number of traumatic experiences of her childhood, when she experienced an alcoholic father, domestic violence, early loss of her mother, and also in her later life when she experienced unsatisfactory marriages with violence and alcoholism, lack of support and financial dependence of her husband, having a mentally challenged child, who died early, material losses, massive social setback migration problems and her own alcoholism leading to a number of devaluating experiences when she was found drinking at work and fired. The person plans an ambitious working life in the style how she learned to set expectations for her, which she could not fulfill. She covered her failure in alcoholism and, recently, by a non-lethal suicide act but did not revise her plans. She also dealt in this way with the pains and unbearable feeling occurring in situations reminding her of the childhood traumas. She tried to create an image in her social environment she could not live up to. This led to the belief in the psychiatrists that this woman can easily overcome her alcohol problems as she possesses clear insight what the problem is and how to improve her situation.

\section{Interpretation}

Thus, this joint occupational career of the person in recovery is based on the person's wishful thinking and will probably lead to the old traps and disasters. The aim of the here proposed approach is that an occupational career of the person becomes the line along which the therapy and rehabilitation of this person will proceed and a system, which should be developed a new leading to more promising goals. The task of the joint occupational career professional participants is to account for the illness related dynamics and to provide the person with means of developing a new strategy. Thus, their task is not to pull the person down into realistic domains. Very often, the anxieties and fears inhibit the persons so that the joint goal will aim far beyond the persons' target.

This person's overstretching her resources is not based on her self-overestimation but on her untreated traumatic experiences of her childhood described above. The extent of the emotional embedding of a number of occupation-related decisions in the childhood and later life traumas became apparent in the self-confrontation interview, where the subjective meaning of various events and experiences was addressed.

It seems necessary to develop a joint project related to the occupational career of this person which would not distinguish between mental support of this person (treating the depression of the 
person with the hope that her alcoholism and suicidality will diminish as well) and training her for her new job following one rehabilitation philosophy or helping her to obtain a job, as quickly as possible following the philosophy of supported employment.

The aim would be to treat her mental problems she encounters in devising her occupational career. Consequently, the first issue would be to find out which role her traumatizing experiences play in this career, how much she is really planning for herself in joint planning and how much is she trying to please the threatening others which she has to pacify and win. Further, how she can experience a satisfactory working day without having to treat her alarming emotions with alcohol in the evening. How can she get involved in encounters with others, without suffering and, consequently, without avoiding social contacts? Thus, her psychotherapy would not treat her trauma per se but in relationship to how these traumas show in her occupational career and which freedom she gains when these experiences are not influential any more. It is understandable that her occupational involvement will imply a series of other relationship projects, as this is the case in all occupational pursuits. In the case of this person the question of compatibility of these projects could be crucial, as she seems to experience substantial difficulties in successfully intertwine social relationship and self-related projects. Equally, her occupation related memories are associated with a number of traumatic experiences, which in return exercise a strong impact on her selfrelated projects.

Thus, it is not just her suicidality, depression and alcoholism, which should be attended to but her way, how she builds the system of goal-directed processes required by vocational engagement, which should be targeted by any mental health rehabilitation.

A person in recovery in his late fifties, a craftsman, is treated for depression and is planning a new occupational life outside of his firm where after a number of years he felt not supported and his work not satisfactory valued. This planning is entirely based on avoidance of the situation he considers threatening and would not make sense to pursue, as an alternative employment might be very difficult to obtain because of the age of the person.

\section{Interpretation}

In a conventional treatment the therapist might be satisfied when the patient loses his alarming arousal, fear, anxiety, depression and feeling of threat even if it is because of new environment. Thus, assuming that the person would not find a new job and would never agree to return into the old one, we are risking several hundred thousand Swiss Francs of compensation money paid for disability pension instead of dealing with these fears as the basis of avoidance. An occupational project, in which the person learns to deal with various social situations, to give himself the required feedback about his work and to 'read' his superior's communication might be more helpful.

A young man, a Swiss born son of a migrant worker (who, according to his son, never learned the language to achieve some independence in dealing with the local institutions and probably suffered lifelong devaluation and discrimination) never learned to deal with his emotions encountering treatment he considered unfair during his working time until he was not able to take it anymore and connected all these unfair acts to a whole threatening network which he must avoid in his future occupational projects, making it very difficult for him to find any other employment. However, sending him back in the old job after some treatment for his depression and his paranoid condition makes his state only worse.

\section{Interpretation}

In the new view his joint cultural projects and his identity projects would have to be dealt with as being closely intertwined with his occupational career and his mental health. The understanding of the trans-generational cultural projects and their emotional anchoring is a crucial conception to understand the projects of this person in recovery. Without that the person would not understand his situation and his responses and will be getting deeper and deeper in this selfdeclared fight for fairness. His emotional states and anchoring of his problems will be dealt with as embedded in his career and not as a biography independent disorder.

As his inability to return into his vocation has debilitating consequences for his occupational career this man could be in sheltered employment for the rest of his life thus causing social costs of several millions.

Another person in recovery, a young man, electro technician, who changed into computer business where he found the work too challenging and increasingly difficult to master, felt that he cannot return to this work with computer people whom he found shallow and not serious and reliable enough. Fighting with his gaps in training he developed a whole justifying system, which he employs in avoiding the whole branch of computer industry. He will be treated for depression and his drinking habits he developed in the course of dealing with his problems.

\section{Interpretation}

His intensive search for someone to blame for his failure indicates his problems in accepting the necessity for change. Consequently, overcoming his current depression might help in energizing his life but without making sure that he can follow ways in which he is successful and abandon less successful ones without questioning his self-worth he will not develop a useful and adaptable occupation related project. Describing this interdependence of various issues, it becomes understandable that the proposed conceptualization might provide a ground at which the participating mental health rehabilitation professionals can achieve substantial synergies in their work as they organize their work around a joint task with a particular relevance for patients works success.

A female person in recovery, early forties indicates that she has an attitude to her problems of 'pretending to be dead' as she feels substantially challenged by these issues. Consequently, being dead she cannot do anything.

\section{Interpretation}

With this attitude she cannot be successful. If she is joined in this approach, she will be supported in her avoiding. A successful occupational career related joint project would have to address this issue. Although this avoiding might not sound critical for the person's mental health it is critical for her occupational career. This is only one of the issues, which become salient as soon as the described stance is applied calling for the proposed integrative approach. The social workers should ask the psychotherapists to work with the person on these issues in order to develop a project rooted in her resources and not wrapped around her avoiding practices. 
The background information to the occupational and vocation career issues was won mainly through the technique of selfconfrontation interview described above. While the conventional interview conducted by a social worker or a vocational rehabilitation professional reveals the person's in recovery vocational career and its social embedding the following self-confrontation interview conducted by a psychotherapist reveals the vocational career emotional and biographical embedding thus providing the career related issues to deal with in a psychotherapy. Thus, in such a procedure it is possible to define a joint vocational career and related projects all participants could work on instead of hoping to restore patients' generic abilities. These projects will be constructed and developed through persons' participation in processes outside of the mental health system which really matter for his personal standing in the society and his or her biography. ${ }^{19}$

\section{Conclusion}

These summaries of the persons' interviews clearly indicate that occupational and vocational projects are an important way of focusing on the post-inpatient treatment occupational and vocational issues. They also indicate that in developing such a project all rehabilitation efforts should be concentrated on it and that this project should be the axis and dimension of any psychotherapy. Consequently, it is important that social workers and occupational therapists or vocational rehabilitation professionals help in outlining this dimension, that psychotherapist will indicate which strategies could be revised being rooted in a mental problem of the persons and that this project then serves as a line and focus of treatment. This particularly is important in times when reduction of the length of stay became an important organizational target. It often is suggested that the aim of the inpatient treatment is to stabilize the person's mental health condition and to outline the way in which the post-inpatient treatment should proceed. While providing the specific referrals for the persons in recovery might cover the institutional and organizational, that is, structural side of this outlined way of the out-patient-treatment, the processual and dynamic way in which several professionals would cooperate is unclear. We propose that this thinking could utilize the conceptualization of goal-directed systems in forms of joint action, projects and career. Thus, the communication during the in-patient stay would evolve around this conceptualization with the aim to work out an outline of a clear goal-directed process serving the aims of the treatment and the systems of persons' in recovery careers of which the occupational projects are an important part. As the person is an important agent in these goal-directed systems, the communication with the person will function as constructing processes of these goaldirected projects and career. Consequently, it is important that these systems are congruent with the goals set for the rehabilitation. It often is not the case as indicated in the findings. Developing an avoidance project or a pretending project is not helpful in achieving integrative occupational goals. Additionally, this conceptualization offers not only a view of seeing the person's occupational resources getting focused at but also a promotion of a collaborative, goal directed organization of the participating professional.

This understanding described above is compatible with the way of thinking developed by the World Health Organization in support of the philosophy of the WHO International Classification of Functions. It suggests that the stress on abilities as formulated in the previous version of this system is not necessary the most decisive feature of the rehabilitation and thus it has been replaced by a focus on activity and participation.

Following this philosophy, it would be helpful if the conceptualizations of all professions participating in the rehabilitation of the mental health patients would shift their focus from the patients' dispositions to the persons' joint projects and career. It is a process where they all could meet. An occupational/vocational career with the related joint projects would represent one of the most important careers, which determines the degree of social integration of the former mental health inpatients.

In psychotherapy, understanding of the abilities could be compared to the thinking of psychotherapy work as independent of everyday careers and projects, just related to people's generic potentials. However, some of the recent conceptualizations in occupational/ vocational career thinking tell us that the joint occupational career projects often are the decisive powers in occupational career development. ${ }^{16}$

Consequently, monitoring the existing joint occupational projects and outlining the principles of helpful joint occupational career projects are important strategies in exploring and designing this approach. Therefore, the psychiatric rehabilitation should focus on the occupational and other careers utilizing the methods and conceptualizations proposed above. Individual propositions of this approach could be found in various rehabilitation ideas. Currently, the empirical results indicate that the supported employment is one of the most effective vocational rehabilitation.

It has been suggested ${ }^{20}$ that one of the six principle of the IPS (Individual Placement and Support) model of supported employment for people with severe mental illness ${ }^{21,22}$ is integration of rehabilitation and mental health. ${ }^{24}$ In that rehabilitation is understood as an integral component of mental health treatment, rather than a separate service. This is an important proposition providing a basis for a joint vocational career related project in which psychotherapists, social workers, occupational therapists and vocational rehabilitation professionals can participate together with persons in recovery and others in pursuing the vocations goals.

A cardinal feature of IPS is close integration of vocational rehabilitation and mental health treatment. Integration includes the establishment of formal and informal relationships between vocational and mental health staff members, with the intention of facilitating mutual respect and communication between case managers and employment specialists, as well as shared decision making and coordinated planning and interventions.

Traditional methods of vocational rehabilitation (assessment, training, placement) have proved to be largely ineffective. ${ }^{25}$ The IPS principles resonate with a larger body of research suggesting that direct methods of intervention are better than stepwise methods, that integrated approaches are better than brokered approaches, and that assisting people to adapt to specific environments, rather than providing generic training, is more effective. ${ }^{26}$

All these conceptualizations support the above notion of a joint occupational career related project as it also provides an integrative approach, which, however, is theoretically based. As indicated in the interview summaries above, the occupational/vocational career as monitored in the interview performed by occupational therapists 
and social workers with person in recovery revealed an impaired construction influenced by the person's mental health problems.

The interviews of occupational therapists and the social workers clearly introduced the post hospitalization occupational career issues as well as other careers of an independent social life. Considering the main tasks of the psychiatric rehabilitation, to integrate the person in the social life outside of the psychiatric services, it is plausible to postulate that the projects and career discussed in the interviews with occupational/vocational therapists and social workers are the most relevant and that the psychiatric treatment should evolve around these dimensions.

Occupation is a potent medium for eliciting unarticulated, unprocessed, felt experiences that can potentially prompt emotions of joy and images of a future self. However, it has also been recognized that reliving past occupations can backfire because of the felt meaning that leads to anger or anxieties. ${ }^{27}$

Research in the area of occupational science ${ }^{28,29}$ and clinical 6. reasoning ${ }^{30}$ provide a framework for analyzing the value of occupational projects as a process toward the goal of reconstituting the self or living an adaptive process. According to the occupational science literature, occupations typically do not happen in a random fashion; persons continue to create themselves through what they do.

The current conventional concept is that the psychiatric treatment deals with the mental disorder and that the social workers help in solving the social problems of the patients and prepare the patient's life after the hospitalization. Similarly, the occupational therapist assesses the patients' abilities to work, if necessary, develop further additional required skills and provide an optimal match between patient's abilities and a job following the discharge of the patients from the inpatient treatment. However, the launching of people into their occupational/vocational career on the one hand and even the evaluating of rehabilitation patient on the other is not developed around the paradigm of disposition and abilities matched to certain jobs.

The vocational counseling underwent a substantial change in the last 20 years. New approaches, criticism indicating massive shortcomings of the traditional approach received wide publicity. In particular, the conceptualization, the methodology of the information collecting, the research, the scope of the counselor's work, the basic philosophy of the counselors, their image of human being and many other issues were discussed. ${ }^{9}$ These discussions should also be understood before the backdrop of the recent social changes and the expectation related to thefuture of career. ${ }^{31}$ They should find a way into the mental health persons' occupational rehabilitation in the attempt to improve its effectiveness. It is suggested here that the described approach could present a first step and methodology in the desired direction. The empirical material collected for exploratory purposes indicates the heuristic value of this view. We believe that this conceptualization would help changing psychiatric rehabilitation into the science of possibilities. ${ }^{32}$

\section{Acknowledgments}

None.

\section{Conflicts of interest}

The authors declare no conflict of interest.

\section{References}

1. Young RA, Valach L, Collin A. A contextualist explanation of career. In: D Brown \& Associates, 4th edn. Career choice and development. San Francisco: Jossey-Bass. 2002;206-252.

2. Garske GG. The challenge of rehabilitation counselors: Working with people with psychiatric disabilities. Journal of Rehabilitation. 1999;65:2125.

3. VandenBoom DC, Lustig DC. The relationship between employment status and quality of life for individuals with severe and persistent mental illness. Journal of Applied Rehabilitation Counseling. 1977;28:4-8

4. National Institute of Disability and Rehabilitation Services. Rehab brief: Strategies to secure and maintain employment for people with long-term mental illness. 1993;10:1-4.

5. Marshak, LE, Bostick D, Turton L. Closure outcomes for clients with psychiatric disabilities served by the vocational rehabilitation system. Rehabilitation Counseling Bulletin. 1990;33:247-250.

6. Ruesch P, Meyer PC, Graf J, et al. Employment situation of psychiatric in-patients with schizophrenic or affective disorders. Psychiatr Prax. 2002;2:68-75.

7. Abramovich T. General hospital psychiatry: Implications for occupational therapy - One case study. Medicine and Law. 1993; 12:363-357.

8. Meyer A. The philosophy of occupational therapy. American Journal of Occupational Therapy.1922;31:639-642.

9. Brown D. Associates. Career choice and development. 4th edn. San Francisco: Jossey-Bass. 2002;206-252.

10. Collin A, Young RA. New directions for theories of career. Human Relations. 1986;39:837-853.

11. Collin A, Young RA. Career development and hermeneutical inquiry: Part II - Undertaking hermeneutical research. Canadian Journal of Counselling. 1988;22:191-201.

12. Young RA, Borgen WA. Methodological approaches to the study of career. New York: Praeger Publishers. 1990.

13. Young RA, Collin A. editors. Constructivism, Social Constructivism and Career. Special Issue of the Journal of Vocational Behavior. 2004;64(3):373-532.

14. Valach L, Young RA. Some cornerstones in the development of a contextual action theory of career and counseling. International Journal of Educational and Vocational Guidance. 2004;4(1):61-81.

15. Young RA, Valach L, Dillabough JA, et al. Career researchfrom an action perspective: The self-confrontation procedure. Career Development Quarterly. 1994;43:185-196.

16. Young RA, Valach L, Ball J, et al. Career development as a family project. Journal of Counseling Psychology. 2001;48(2):190-202.

17. Valach L, Cranach M, Kalbermatten U. Social meaning in the observation of goal directed action. Semiotica. 1988;71(3/4):243-259.

18. Valach L, Young RA, Lynam MJ. Action theory. A primer for applied research in the social sciences. Westport, CT: Praeger. 2002.

19. Young RA, Valach L. The construction of career through goaldirected action. In: RA Young, A Collin. editors. Constructivism, social constructivism and career. Special Issue of the Journal of Vocational Behavior. 2004;64(3):499-514.

20. Bond GR. Principles of the individual placement and support model: empirical support. Psychiatric Rehabilitation Journal. 1988; 22(1):11-23.

21. Becker DR, RE. A working life: The individual placement and support 
(IPS) program. Concord, NH: New Hampshire-Dartmouth Psychiatric Research Center. 1993.

22. Becker DR, Drake RE. Individual placement and support: A community mental health center approach to vocational rehabilitation. Community Mental Health Journal. 1994;30(2):193-206.

23. Drake RE, Becker DR. The individual placement and support model of supported employment. Psychiatric Services. 1996;47: 473-475.

24. Harding CM, Strauss JS, Hafez H, et al. Work and mental illness. I. Toward an integration of the rehabilitation process. Journal of Nervous and Mental Disease. 1987;175:317-326.

25. Bond GR. Vocational rehabilitation. In: RP Liberman. Editor. Handbook of psychiatric rehabilitation. New York. Macmillan. 1992;244-275.

26. Mueser KT, Drake RE, Bond GR. Recent advances in psychiatric rehabilitation for patients with severe mental illness. Harvard Review of Psychiatry. 1997;5:123-137.
27. Jackson J. The value of occupation as the core of treatment: Sandy's experience. Am J Occup Ther. 1998;52(6):466-473.

28. Clark F. Occupation embedded in a real life: Interweaving occupational science and occupational therapy, 1993 Eleanor Clarke Slagle lecture. American Journal of Occupational Therapy. 1993;47:1067-1078.

29. Zemke R, Clark F. Occupational science: The evolving discipline. Philadelphia: FA Davis. Editor. 1996.

30. Mattingly C, Fleming M. Clinical reasoning: Forms of inquiry in a therapeuticpractice. Philadelphia: FA Davis. 19993.

31. Young AR. Collin A. The future of career. Cambridge: Cambridge University Press. 2000.

32. Anthony WA. Psychiatric rehabilitation and the science of possibilities. Psychiatric Rehabilitation Journal. 2007;28(4):1-2. 